\title{
The Impact of E-waste Occupational Exposure on Male Reproductive Health
}

\author{
Zhihai Deng, Yude Hong, Baiwei Tang, Weibo Liang* \\ Department of Urology, the First Affiliated Hospital of Jinan University, Guangzhou, Guangdong, People's Republic of China
}

Email address:

wbl_jnu2006@sina.com (Weibo Liang)

${ }^{*}$ Corresponding author

\section{To cite this article:}

Zhihai Deng, Yude Hong, Baiwei Tang, Weibo Liang. The Impact of E-waste Occupational Exposure on Male Reproductive Health. American Journal of Health Research. Vol. 4, No. 3, 2016, pp. 70-74. doi: 10.11648/j.ajhr.20160403.16

Received: April 25, 2016; Accepted: May 11, 2016; Published: May 28, 2016

\begin{abstract}
Electrical and electronic waste (e-waste) contains multiple toxic materials. However, there is currently a lack of exposure data on workers in formal recycling plants. This study aims to observe the influence of electronic waste (e-waste) on male's reproductive health and to provide a theoretical foundation for improving the occupational safety. A survey and sample collections were performed based on 210 workers in e-waste recycling plant as the exposure group and 210 residents who worked at the same area but not exposed to e-waste (other jobs) as the control group. Semen sperm analysis and TUNEL assay were applied to detect the apoptotic rate and single comet assay to detect DNA damage. The survey results showed that infertility rate of e-waste recycling workers was significantly higher than that of non-occupationally exposed workers $(P<0.05)$; e-waste occupationally exposed workers showed markedly higher rate of prostatitis, urethritis, abortion and preterm birth of their spouses $(P<0.05)$. The percentage of sperm concentration, motile sperm, 'a' level sperm, ' $\mathrm{a}+\mathrm{b}$ ' level sperm and live sperm of the exposure group were higher than control group $(P<0.05)$. TUNEL assay revealed that the apoptotic rate of sperms in the exposure group was higher too $(P<0.05)$. Further, the sperm comet length, tail length, tail DNA \%, Olive tail moment were significantly different between the two groups $(P<0.05)$. In general, we concluded that occupational exposure to e-waste led to asthenospermia and increased male infertility. Occupational exposure to e-waste increased the sperm apoptosis rate and sperm DNA damage.
\end{abstract}

Keywords: Electronic Waste, Male Reproductive Health, Semen, TUNEL, Sperm Comet Assay

\section{Introduction}

Since the $20^{\text {th }}$ century, technological innovation and the continued marketing expansion have led to the accumulation of electronic equipment, generating a lot of electronic waste (e-waste). It is estimated that there are 42 million tons of newly generated e-waste every year, globally $[1,2]$. China becomes one of the largest e-waste production and the importing country. In 2010, there are 2.3 million tons of e-waste were produced in China, after the United States [3-5]. In 2007, there are over 0.7 million Chinese workers engaged in e-waste recycling, $98 \%$ of which are informal recycling [6]. They mainly take the family-owned operations, using the backward recovery procedure, which not only affect the health of the workers, but also pollute the atmosphere, leading to diseases among other people via contacting with dust, radioactive, other toxic and hazardous substances $[7,8]$. The component of e-waste is complex, containing more than 1000 substances, including lead, zinc, chromium, nickel, cadmium, copper and other heavy metals, which would largely affect the public health [9]. These substances cannot be easily metabolized and continued to accumulate, interfering the endocrine system, immune system, nervous system and reproductive system. Moreover, heavy metals induce oxidative stress response, cell apoptosis and DNA damage. The male reproductive system is susceptible to interference by external factors [10]. This study aims to investigate the effect of e-waste exposure on male productive health. 


\section{Materials and Methods}

\subsection{Subject Selecting}

Cluster sampling method is applied, occupationally exposed and non-occupationally exposed populations aged 20-25 years old that working more than 2 years at electronic waste dismantling plant at Long tang of Qingyuan city were included. The investigation criteria includes the following five aspects: (1) the general information (age, race, educational level, marriage and etc.), (2) living habit (drinking, smoking, diet and etc.), (3) working environment (whether or not in family owned working plant, of area around $15 \mathrm{~m}^{2}$, narrow, poor ventilation, substantially closed, at a temperature of about 30-32 degrees, surround by electronic waste, poor sewage system, sewers, heavy electronic waste and heavy metals odor), (4) general health and (5) reproductive health (prostatitis, urethritis, epididymitis, infertility and reproductive abnormalities events).

Exclusion: subjects with (1) hypertension, diabetes or thyroid diseases; (2) with chronic infection of the reproductive system; (3) a history of mumps virus or a history of known infertility; (4) alcoholics; (5) heavy smokers. If the spouse is not engaged in occupational exposure, but with the presence of cryptorchidism or hypospadias or other congenital reproductive dysfunction, the questionnaire will be fully recovered. Quality control: surveys were performed 'one to one' or 'one to many'. The questionnaire was strictly inspected after the survey, to help the irregular fill the form again. The finished questionnaire was strictly ordered to establish an Excel database.

\subsection{Semen Sample Collection}

After the approval of ethical review committee of the First Affiliated Hospital of Jinan University and the signed written informed consent, semen samples were collected as follows: (1) before the collection: subjects were told of abstinence for 3-7d; (2) during the collection: subjects should get the semen sample by way of masturbation in a disposable sterile plastic specimen box. The semen sample cannot be spilled outside the box. Because the sperm density of the semen is especially high in the initial part of the ejaculation, which has a large influence on the result. The examination was taken $30 \mathrm{~min}$ after the collection.

\subsection{Detection Indicator}

Sperm concentration and vitality were automatically analyzes by the CASA system. The apoptosis was detected by TUNEL and sperm comet assay. According to the guidelines of the $5^{\text {th }}$ edition of 'WHO laboratory manual for the Examination and processing of human semen', the semen samples were analyzed by WeiLi Color Sperm Quality Analysis System (WLJY-9000, Beijing, China) under the guide of an experienced inspection competent technician.

\subsection{TUNEL Assay}

The TUNEL assay was performed using a kit (Roche
Diagnostics GmbH, Mannheim, Germany). The sperm suspension was centrifuged at $800 \mathrm{~g}$ for $10 \mathrm{~min}$; the supernatant was discarded and the remaining pellet was resuspended with PBS. Sperm samples were smeared on microscope slides, fixed with $3.5 \%$ formaldehyde in PBS for $30 \mathrm{~min}$ at $4{ }^{\circ} \mathrm{C}$ and permeabilized with $0.1 \%$ Triton X-100 in $0.1 \%$ sodium citrate. After washing with PBS, the slides were incubated in the dark at $37^{\circ} \mathrm{C}$ for $1 \mathrm{~h}$ in TUNEL reaction mixture containing labelled nucleotides and enzyme terminal transferase. After stopping the enzyme reaction, the slides were washed in PBS and counterstained with PI at $2 \mu \mathrm{g} / \mathrm{ml}$ in PBS. Then the slides were mounted and observed in a fluorescence microscope (Nikon, Japan).

\subsection{Sperm Comet Assay}

The sperm comet assay was carried out essentially as previously described $[11,12]$. Sperm sample was suspended in $100 \mu \mathrm{l}$ of $1 \%(\mathrm{w} / \mathrm{v})$ low melting point agarose. From this suspension, $100 \mu \mathrm{l}$ was applied to the surface of a microscope slide (pre-coated with $1 \%$ normal melting point agarose) to form a microgel and allowed to set at $4^{\circ} \mathrm{C}$ for $5 \mathrm{~min}$. Slides were dipped in cell lysis buffer $(2.5 \mathrm{M} \mathrm{NaCl}, 100 \mathrm{mM}$ EDTA, $10 \mathrm{mM}$ TrisCl, $\mathrm{pH} 10.0$ containing $1 \%$ triton $\mathrm{X}-100$ and 40 $\mathrm{mM}$ dithiothreitol) for $24 \mathrm{~h}$ at room temperature and protected from light. Following the lysis, RNase A and proteinase $\mathrm{K}$ was added to the lysis solution at $37^{\circ} \mathrm{C}$ for $24 \mathrm{~h}$. Following cell lysis, all slides were washed three times with deionized water at $10 \mathrm{~min}$ intervals to remove salt and detergent from the microgels. Slides were placed in a horizontal electrophoresis unit and were allowed to equilibrate for $20 \mathrm{~min}$ with running buffer before electrophoresis $(0.60 \mathrm{~V} / \mathrm{cm}, 250 \mathrm{~mA})$ for $30 \mathrm{~min}$. After electrophoresis, slides were then neutralized with $0.4 \mathrm{M}$ Tris (pH 7.5), stained with SYBR Green I $(1: 10,000)$ for $1 \mathrm{~h}$ and covered with cover slips. The comet images were analyzed by Comet A1.0 software (Cell Biolabs, San Diego, CA, USA)

\subsection{Statistical Analysis}

SPSS 18.0 (PASW, Statistics, IBM) were used to analyze the data. Data were presented as mean \pm SD. Significance of differences were determined using ANOVA and the Bonferroni post hoc test, except sperm Comet parameters, which were evaluated using Kruskal-Wallis ANOVA and the Mann-Whitney $U$-test. Chi-square test was used between non-variable data. $P<0.05$ was considered significant.

\section{Results}

In this study, 210 occupationally exposed and 230 non-occupationally exposed people were included. As shown in Table 1, the general parameters including age, educational level, marriage, smoking and drinking are very close between the two groups, showing no significant differences.

The incidence of epididymitis and spouse' ectopic pregnancy in both the two groups showed no significant difference $(P>$ 0.05 , Table 2). But the incidence of prostatitis and urethritis, the 
number of abortions, premature delivery and male infertility were significantly increased, compared with the non-occupationally exposed group $(P<0.05$, Table 2$)$.

Table 1. Information of both occupationally and non-occupationally exposed male reproductive health groups.

\begin{tabular}{|c|c|c|c|}
\hline \multicolumn{2}{|c|}{ Parameters } & \multirow{2}{*}{$\begin{array}{l}\begin{array}{l}\text { Occupationally } \\
\text { exposed group }\end{array} \\
29.64 \pm 10.34\end{array}$} & \multirow{2}{*}{$\begin{array}{l}\text { Non-occupationally } \\
\text { exposed group }\end{array}$} \\
\hline Age & & & \\
\hline \multirow{3}{*}{$\begin{array}{l}\text { Educatio } \\
\text { n level }\end{array}$} & Primary or below & 8 & 10 \\
\hline & $\begin{array}{l}\text { Junior high or high } \\
\text { school }\end{array}$ & 184 & 197 \\
\hline & College or above & 18 & 23 \\
\hline \multirow{2}{*}{ Marriage } & Married & 187 & 210 \\
\hline & Unmarried & 23 & 20 \\
\hline Smoking & & 156 & 162 \\
\hline Drinking & & 127 & 141 \\
\hline
\end{tabular}

Table 2. Reproductive health situation between the two groups.

\begin{tabular}{|c|c|c|c|c|c|}
\hline \multirow[t]{2}{*}{ Parameters } & \multicolumn{2}{|c|}{$\begin{array}{l}\text { Occupationally } \\
\text { exposed group }\end{array}$} & \multicolumn{2}{|c|}{$\begin{array}{l}\text { Non-occupationall } \\
\text { y exposed group }\end{array}$} & \multirow[b]{2}{*}{$P$} \\
\hline & n & $\%$ & $\mathbf{n}$ & $\%$ & \\
\hline Prostatitis ${ }^{\boldsymbol{\Lambda}}$ & 58 & 27.62 & 34 & 14.78 & 0.021 \\
\hline Urethritis ${ }^{\boldsymbol{\Delta}}$ & 37 & 17.62 & 17 & 7.39 & 0.014 \\
\hline Epididymitis & 19 & 9.05 & 12 & 5.22 & 0.053 \\
\hline $\begin{array}{l}\text { Number of spouse' } \\
\text { abortion }\end{array}$ & 14 & 7.49 & 3 & 1.43 & 0.002 \\
\hline $\begin{array}{l}\text { Number of spouse' } \\
\text { premature delivery }\end{array}$ & 18 & 9.63 & 8 & 3.81 & 0.001 \\
\hline $\begin{array}{l}\text { Number of spouse' } \\
\text { ectopic pregnancy rate }\end{array}$ & 3 & 1.6 & 2 & 0.95 & 0.058 \\
\hline Male of infertility & 10 & 5.35 & 2 & 0.95 & 0.000 \\
\hline
\end{tabular}

A denotes Chi-square test, $P<0.05$.

Table 3. Semen activity between the two groups.

\begin{tabular}{lll}
\hline \multirow{2}{*}{ Parameters } & $\begin{array}{l}\text { Occupationally } \\
\text { exposed group }\end{array}$ & $\begin{array}{l}\text { Non-occupationally } \\
\text { exposed group }\end{array}$ \\
\cline { 2 - 3 } & $\mathbf{M} \pm$ SD & M \pm SD \\
\hline Sperm concentration $\left(10^{6} / \mathrm{ml}\right)$ & $30.66 \pm 15.02^{\mathbf{\Lambda}}$ & $52.27 \pm 16.12$ \\
Total sperm number $\left(10^{6}\right)$ & $145.57 \pm 67.08^{\mathbf{\Delta}}$ & $208.08 \pm 65.71$ \\
'a' level sperm $(\%)$ & $12.08 \pm 3.45^{\mathbf{\Delta}}$ & $37.04 \pm 1.61$ \\
'a+b' level sperm $(\%)$ & $30.92 \pm 2.96^{\mathbf{\Delta}}$ & $65.84 \pm 1.25$ \\
Live sperm $(\%)$ & $38.68 \pm 4.08^{\mathbf{\Delta}}$ & $70.28 \pm 3.45$ \\
\hline
\end{tabular}

$\Delta$ denotes t-test, $P<0.05$.

Table 4. Sperm apoptosis rate by TUNEL between the two groups.

\begin{tabular}{|c|c|c|c|}
\hline \multirow{2}{*}{ Group } & Apoptotic rate of sperm (\%) & \multirow[b]{2}{*}{$t$} & \multirow{2}{*}{$\boldsymbol{P}$} \\
\hline & $\mathbf{M} \pm \mathbf{S D}$ & & \\
\hline \multirow{2}{*}{$\begin{array}{l}\text { Occupationally exposed } \\
\text { group } \\
\text { Non-occupationally } \\
\text { exposed group }\end{array}$} & $38.14 \pm 4.08$ & \multirow{2}{*}{3.65} & \multirow{2}{*}{0.001} \\
\hline & $27.00 \pm 2.90$ & & \\
\hline
\end{tabular}

Compared with the non-occupationally exposed group, the percentage of sperm concentration, motile sperm, 'a' level sperm, ' $a+b$ ' level sperm and live sperm of the exposure group were significantly higher than control group (Table $3, P<$ $0.05)$. TUNEL assay revealed that the apoptotic rate of sperms in the exposure group was significantly higher (Table $4, P<$ 0.05). Further, the sperm comet length, tail length, tail DNA \%, Olive tail moment were significantly different between the two groups (Table 4, $P<0.05$; Figure 1).
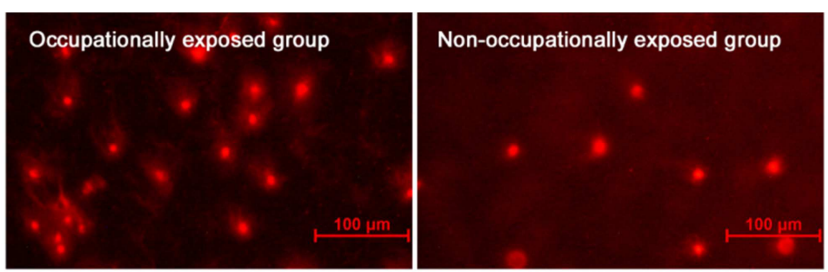

Figure 1. Representative images of sperm comet assay showed between the two groups.
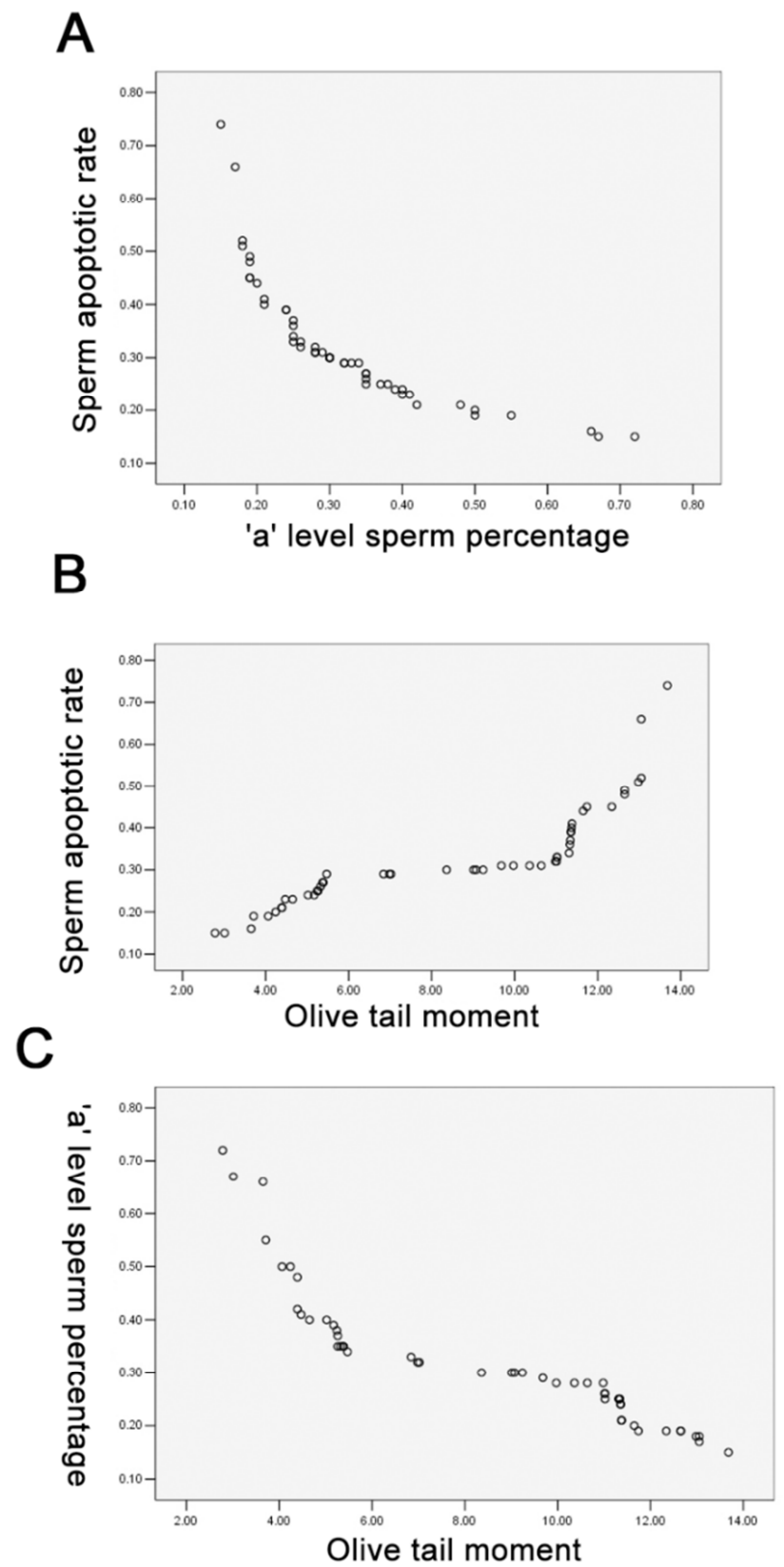

Figure 2. Linear regression scatter plots of sperm apoptotic rate, 'a' level sperm percentage and Olive tail moment.

We summed the results from all the two groups and found that the linear regression equation between sperm apoptosis rate and ' $a$ ' level of sperm percentage was $y=0.572-0.761 \mathrm{x}$, the coefficient of determination was 0.677 (Figure 2A); That between sperm apoptotic rate and Olive tail moment was 
$\mathrm{y}=0.067+0.031 \mathrm{x}$, the coefficient of determination was 0.742 (Figure 2B); That between ' $\mathrm{a}$ ' level of sperm percentage and Olive tail moment was $y=0.613-0.34 x$, the coefficient of determination was 0.795 (Figure 2C). These data indicate that the productive health is closely related to their occupationally exposure to e-waste.

Table 5. Sperm comet results between the two groups.

\begin{tabular}{lll}
\hline \multirow{2}{*}{ Parameter } & $\begin{array}{l}\text { Occupationally } \\
\text { exposed group }\end{array}$ & $\begin{array}{l}\text { Non-occupationally } \\
\text { exposed group }\end{array}$ \\
\cline { 2 - 3 } & $\mathbf{M} \pm$ SD & $\mathbf{M} \pm$ SD \\
\hline sperm comet length $(\mu \mathrm{m})$ & $43.68 \pm 7.92^{\mathbf{\Delta}}$ & $29.60 \pm 6.78$ \\
tail length $(\mu \mathrm{m})$ & $35.61 \pm 6.13^{\mathbf{\Delta}}$ & $22.18 .6 \pm 4.72$ \\
tail DNA \% & $51.23 \pm 6.07^{\mathbf{\Delta}}$ & $33.55 \pm 6.99$ \\
Olive tail moment & $11.45 \pm 1.17^{\mathbf{\Delta}}$ & $5.4 \pm 1.78$ \\
\hline
\end{tabular}

$\Delta$ denotes t-test, $P<0.05$.

\section{Discussion}

Heavy metals can directly affect the reproductive organs or indirectly affect the reproductive function via interfering with the neuroendocrine system. Any influence would decrease the number of sperm; induce sperm deformity, decreasing sperm chromosome stability or DNA damage to reduce sperm motility [13-15]. Sperm membrane damage can affect sperm motility and increase the difficulty of the pregnancy; DNA damages will lead to infertility, miscarriage and fetal malformation [16, 17]. TUNEL assay is the common method to detect cell apoptosis, easy and convenient, with high sensitivity $[18,19]$. Comet assay is also called single cell gel electrophoresis, which is used for detecting DNA damage, also with high sensitivity as in this study [9].

This study revealed that e-waste occupationally exposed workers showed higher rate of prostatitis, urethritis, abortion and preterm birth of their spouses. The percentage of sperm concentration, motile sperm, 'a' level sperm, 'a+b' level sperm and live sperm of the exposure group were higher than control group. TUNEL assay showed that the apoptotic rate of sperms in the exposure group was higher too. Further, the sperm comet length, tail length, tail DNA \%, Olive tail moment were significantly different between the two groups. By linear regression analysis, we found that sperm apoptosis rate, ' $a$ ' level sperm and Olive tail moment had a linear relationship in pairwise comparison. Taken together, these data indicate that the sperm function of occupationally exposed population is largely affected.

Occupational disease can be induced via contacting with dust, radioactive and other toxic and hazardous substances during their professional activities. For e-waste exposure, the air they breathe, the objects they reached and the food they eat are all toxic. Although they show less acute poisoning, the accumulation of these toxics inside would largely affect the health. Our results show that e-waste exposure would affect male reproductive health, which is consistent with other studies [20,21]. Although there are different views on whether or not the semen quality is decreasing, the environmental pollution is commonly accepted as the main critical influence factor [22, 23]. Epidemiological research shows that in e-waste recycling area, the incidence of male reproductive disease significantly increased. In order to lessen the occupational exposure risk, the government should strengthen the construction on industrial standards, to enact related policies to induce the normalized development of e-waste recycling industry. This study would raise the awareness for the occupational protection for e-waste industry.

\section{Conclusion}

By large scale survey and experimental detection, this study reveal that occupational e-waste exposure would increase the incidence of prostatitis, urethritis, abortion and preterm birth of their spouses and also can reduce sperm concentration, motile sperm and live sperm percentage. E-waste exposure induces the sperm apoptosis and leads to DNA damage. In all, our data indicate that the sperm function of occupationally exposed population is largely affected.

\section{References}

[1] Chan, J. K. and M. H. Wong, A review of environmental fate, body burdens, and human health risk assessment of PCDD/Fs at two typical electronic waste recycling sites in China. Sci Total Environ, 2013, 463-464: 1111-23.

[2] Directive 2001/20/EC of the European Parliament and of the Council of 4 April 2001 on the approximation of the laws, regulations and administrative provisions of the member states relating to the implementation of good clinical practice in the conduct of clinical trials on medicinal products for human use. Med Etika Bioet, 2002, 9(1-2): 12-9.

[3] Sthiannopkao, S. and M. H. Wong, Handling e-waste in developed and developing countries: initiatives, practices, and consequences. Sci Total Environ, 2013, 463-464: 1147-53.

[4] Xu, X., Y. Zhang, T. A. Yekeen, Y. Li, B. Zhuang, and X. Huo, Increase male genital diseases morbidity linked to informal electronic waste recycling in Guiyu, China. Environ Sci Pollut Res Int, 2014, 21(5): 3540-5.

[5] Chi, X., M. Streicher-Porte, M. Y. Wang, and M. A. Reuter, Informal electronic waste recycling: a sector review with special focus on China. Waste Manag, 2011, 31(4): 731-42.

[6] Ongondo, F. O., I. D. Williams, and T. J. Cherrett, How are WEEE doing? A global review of the management of electrical and electronic wastes. Waste Manag, 2011, 31(4): 714-30.

[7] Wong, C. S., S. C. Wu, N. S. Duzgoren-Aydin, A. Aydin, and M.H. Wong, Trace metal contamination of sediments in an e-waste processing village in China. Environ Pollut, 2007, 145(2): 434-42.

[8] Yu, X. Z., Y. Gao, S. C. Wu, H. B. Zhang, K. C. Cheung, and M.H. Wong, Distribution of polycyclic aromatic hydrocarbons in soils at Guiyu area of China, affected by recycling of electronic waste using primitive technologies. Chemosphere, 2006, 65(9): 1500-9.

[9] Song, Q. and J. Li, A review on human health consequences of metals exposure to e-waste in China. Environ Pollut, 2015, 196: 450-61. 
[10] Jurasovic, J., P. Cvitkovic, A. Pizent, B. Colak, and S. Telisman, Semen quality and reproductive endocrine function with regard to blood cadmium in Croatian male subjects. Biometals, 2004, 17(6): 735-43.

[11] Haines, G. A., J. H. Hendry, C. P. Daniel, and I. D. Morris, Germ cell and dose-dependent DNA damage measured by the comet assay in murine spermatozoaa after testicular X-irradiation. Biol Reprod, 2002, 67(3): 854-61.

[12] Kushwaha, S. and G. B. Jena, Enalapril reduces germ cell toxicity in streptozotocin-induced diabetic rat: investigation on possible mechanisms. Naunyn Schmiedebergs Arch Pharmacol, 2012, 385(2): 111-24.

[13] Xu, B., S. E. Chia, M. Tsakok, and C. N. Ong, Trace elements in blood and seminal plasma and their relationship to sperm quality. Reprod Toxicol, 1993, 7(6): 613-8.

[14] Agarwal, A. and T. M. Said, Role of sperm chromatin abnormalities and DNA damage in male infertility. Hum Reprod Update, 2003, 9(4): 331-45.

[15] Ghobish, A. A., Quantitative and qualitative assessment of flowmetrograms in patients with prostatodynia. Eur Urol, 2000, 38(5): 576-83.

[16] Khalili, M. A., F. Aghaie-Maybodi, M. Anvari, and A. R. Talebi, Sperm nuclear DNA in ejaculates of fertile and infertile men: correlation with semen parameters. Urol J, 2006, 3(3): 154-9.

[17] Giwercman, A., L. Lindstedt, M. Larsson, M. Bungum, M.
Spano, R. J. Levine, and L. Rylander, Sperm chromatin structure assay as an independent predictor of fertility in vivo: a case-control study. Int J Androl, 2010, 33(1): e221-7.

[18] Cocuzza, M., S. C. Sikka, K. S. Athayde, and A. Agarwal, Clinical relevance of oxidative stress and sperm chromatin damage in male infertility: an evidence based analysis. Int Braz J Urol, 2007, 33(5): 603-21.

[19] Erenpreiss, J., S. Elzanaty, and A. Giwercman, Sperm DNA damage in men from infertile couples. Asian J Androl, 2008, 10(5): 786-90.

[20] Zeng, X., X. Xu, H. M. Boezen, and X. Huo, Children with health impairments by heavy metals in an e-waste recycling area. Chemosphere, 2016, 148: 408-15.

[21] Xu, X., X. Zeng, H.M. Boezen, and X. Huo, E-waste environmental contamination and harm to public health in China. Front Med, 2015, 9(2): 220-8.

[22] De Franciscis, P., R. Ianniello, D. Labriola, D. Ambrosio, P. Vagnetti, G. Mainini, C. Trotta, D. Mele, M. R. Campitiello, and F. Caprio, Environmental pollution due to cadmium: measure of semen quality as a marker of exposure and correlation with reproductive potential. Clin Exp Obstet Gynecol, 2015, 42(6): 767-70.

[23] Li, Y., Q. Gao, M. Li, M. Li, and X. Gao, Cadmium, Chromium, and Copper Concentration plus Semen-Quality in Environmental Pollution Site, China. Iran J Public Health, 2014, 43(1): 35-41. 